\title{
Outcomes after Everolimus-Eluting Coronary Stent Implantation in Latin American Women
}

\author{
Vivian G. $\mathrm{Ng}^{1}$, Alexandra J. Lansky ${ }^{2}$
}

C oronary artery disease (CAD) is the leading cause of death in men and women, ${ }^{1}$ and drug-eluting stents (DES) have become a mainstay of percutaneous coronary interventions. Increased attention is now being paid to outcome differences between different geographic regions and genders. Prior studies have shown that Latin Americans have high rates of cardiovascular disease and may have worse outcomes compared to patients in other regions. ${ }^{2-4}$ Latin American women may represent a particularly high-risk patient population, because female gender has also been implicated as a risk factor for worse outcomes after percutaneous coronary interventions (PCls). ${ }^{5,6}$

\section{See page 239}

Prior studies have demonstrated the superior efficacy and safety of the XIENCE ${ }^{\mathrm{TM}} \vee \mathrm{V}$ everolimus-eluting stent (Abbott Vascular, Santa Clara, CA, USA) compared to first-generation DES ${ }^{7,8}$ The XIENCE'TM $\vee$ SPIRIT Women study was the first dedicated prospective multicentre registry of women with de novo CAD. ${ }^{9}$ Approximately $10 \%$ of the study population in the SPIRIT Women registry was from Latin America, allowing for a unique opportunity to evaluate the outcomes of Latin American women compared to other women after receiving the XIENCE ${ }^{\mathrm{TM}} \mathrm{V}$ stent.

In this issue of the Revista Brasileira de Cardiologia Invasiva, Grinfeld et al. ${ }^{10}$ report an analysis of the SPIRIT Women study, specifically comparing outcomes of women in Latin America to women from other regions. Overall, women from Latin America had higher rates of comorbid disease, including higher rates of hypertension, prior myocardial infarction and a family history of CAD. Furthermore, they had worse baseline angiographic characteristics, such as smaller reference vessel diameters and longer lesion lengths. These high rates of known CAD risk factors in Latin American patients have been previously reported and have been implicated in the overall high CAD rates observed in this population. ${ }^{4,11,12}$ Hypertension, diabetes, and prior myocardial infarction rates appeared to be higher in this study when compared to prior studies in Latin American patients. ${ }^{11}$ This is not completely unexpected, since women in general have higher rates of these traditional risk factors than men. This study's all-female population has similar rates of comorbidities compared to other female populations included in clinical trials. ${ }^{13}$

Despite these differences in baseline characteristics, this study found that Latin American women had similar rates of the primary composite endpoint (all-cause death, myocardial infarction and target vessel revascularisation) compared to non-Latin American women $(10.1 \%$ vs. $12.1 \%$; $\mathrm{P}=0.58)$. Furthermore, one-year mortality rates were low in both population subsets $(0.7 \%$ in Latin American women vs. $1.6 \%$ in non-Latin American women). The rates of target vessel failure, death, and myocardial infarction in this study are comparable to results observed in other real world studies. ${ }^{14}$

This analysis offers encouraging data supporting the use of XIENCE $V$ in high-risk populations including Latin American women. Unlike prior studies showing outcome differences in Latin American patients compared to non-Latin American patients, this study demonstrated similar outcomes between women treated with an everolimus-eluting stent. This discrepancy may be related to differences in study inclusion criteria. Prior studies demonstrating worse outcomes in Latin American patients included patients presenting with acute coronary syndromes regardless of whether they were scheduled for invasive management. In these studies, treatment discrepancies between Latin and North American countries were described, and patients in Latin America were less likely to receive revascularisation. ${ }^{4}$ Thus, the less-invasive treatment of patients in Latin America likely contributed to the overall worse

${ }^{1}$ MD. Cardiology fellow. Yale University Medical Center. New Haven, CT, USA.

2 MD. Associate professor and director. Interventional Cardiology Research - Yale University Medical Center. New Haven, CT, USA.

Correspondence to: Alexandra J. Lansky. Yale University Medical Center - PO Box 208017 - New Haven, CT, USA - 06520-8017.

E-mail: alexandra.lansky@yale.edu

Received on: 8/8/2012 • Accepted on: 8/9/2012 
outcomes observed in those studies. ${ }^{4}$ In contrast, the SPIRIT Women registry only included women who were receiving $\mathrm{PCls}$, therefore eliminating confounding invasive versus conservative management differences that could have impacted outcomes. Thus, based on this small patient analysis, women in Latin America likely benefit from the same invasive treatments as women in other geographical regions.

The specific stent used in this study may have also contributed to the outcome similarity observed between geographic populations. In this study, Latin American women had higher rates of small vessels with long lesions, which are known to have worse outcomes compared to patients with larger vessels. ${ }^{11,12}$ Different types of DES are not equivalent in the treatment of small vessel disease, ${ }^{13}$ and prior studies have demonstrated the efficacy of the everolimus-eluting stent in treating small vessel CAD compared to other stent types. ${ }^{11,14}$ The demonstrated beneficial outcomes of the XIENCE ${ }^{T M} \mathrm{~V}$ stent in small vessels and long lesions may have helped narrow the outcome differences observed between Latin American and non-Latin American women. Outcome comparisons between Latin American women and other women treated with stents that are less adequate for small vessel disease have not been reported.

This analysis of a real-world female population offers promising data for the treatment of Latin American women. Despite the higher rates of co-morbid conditions and high-risk angiographic features, Latin American women treated with everolimus-eluting stents for CAD have similar low rates of adverse clinical outcomes compared to other women.

\section{CONFLICT OF INTEREST}

The authors declare no conflicts of interest.

\section{REFERENCES}

1. Roger VL, Go AS, Lloyd-Jones DM, Benjamin EJ, Berry JD, Borden WB, et al. Heart disease and stroke statistics-2012 update: a report from the American Heart Association. Circulation. 2012;125(1):e2-e220.

2. Giugliano RP, Llevadot J, Wilcox RG, Gurfinkel EP, McCabe $\mathrm{CH}$, Charlesworth $\mathrm{A}$, et al. Geographic variation in patient and hospital characteristics, management, and clinical outcomes in ST-elevation myocardial infarction treated with fibrinolysis: results from in TIME II. Eur Heart J. 2001;22(18):1702-15.
3. Lotan C, Meredith IT, Jain A, Feres F, Firszt A, Garcia AF, et al. Clinical outcomes by geographic region for patients implanted with the zotarolimus-eluting stent. Arq Bras Cardiol. 2011;96(5):353-62.

4. Cohen MG, Pacchiana CM, Corbalan R, Perez JE, Ponte Cl, Oropeza ES, et al. Variation in patient management and outcomes for acute coronary syndromes in Latin America and North America: results from the Platelet IIb/IIla in Unstable Angina: Receptor Suppression Using Integrilin Therapy (PURSUIT) trial. Am Heart J. 2001;141(3):391-401.

5. Argulian E, Patel AD, Abramson JL, Kulkarni A, Champney K, Palmer $\mathrm{S}$, et al. Gender differences in short-term cardiovascular outcomes after percutaneous coronary interventions. Am J Cardiol. 2006;98(1):48-53.

6. Watanabe CT, Maynard C, Ritchie JL. Comparison of short-term outcomes following coronary artery stenting in men versus women. Am J Cardiol. 2001;88(8):848-52.

7. Stone GW, Midei M, Newman W, Sanz M, Hermiller JB, Williams J, et al. Comparison of an everolimus-eluting stent and a paclitaxel-eluting stent in patients with coronary artery disease: a randomized trial. JAMA. 2008;299(16):1903-13.

8. Krucoff MW, Rutledge DR, Gruberg L, Jonnavithula L, Katopodis JN, Lombardi W, et al. A new era of prospective real-world safety evaluation primary report of XIENCE $V$ USA (XIENCE V Everolimus Eluting Coronary Stent System condition-of-approval post-market study). JACC Cardiovasc Interv. 2011;4(12):1298-309.

9. Windecker S. Spirit women randomized comparison between everolimus-eluting and sirolimus-eluting stents 9 month angiographic and 1 year clinical follow-up results. EuroPCR 2011

10. Grinfeld L, Agatiello CR, Abizaid A, Belardi J, Lemos P, Marino M, et al. Avaliação do stent coronário eluidor de everolimus XIENCETM $V$ na população feminina latino-americana do estudo de braço único SPIRIT Women: acompanhamento clínico de um ano. Rev Bras Cardiol Invasiva. 2012;20(3):239-46.

11. Claessen BE, Smits PC, Kereiakes DJ, Parise H, Fahy M, Kedhi E, et al. Impact of lesion length and vessel size on clinical outcomes after percutaneous coronary intervention with everolimus-versus paclitaxel-eluting stents pooled analysis from the SPIRIT (Clinical Evaluation of the XIENCE V Everolimus Eluting Coronary Stent System) and COMPARE (Second-generation everolimus-eluting and paclitaxel-eluting stents in real-life practice) randomized trials. JACC Cardiovasc Interv. 2011;4(11):1209-15.

12. Elezi S, Kastrati A, Neumann FJ, Hadamitzky M, Dirschinger J, Schomig A. Vessel size and long-term outcome after coronary stent placement. Circulation. 1998;98(18):1875-80.

13. Togni $M$, Eber $S$, Widmer J, Billinger $M$, Wenaweser $P$, Cook $S$, et al. Impact of vessel size on outcome after implantation of sirolimus-eluting and paclitaxel-eluting stents: a subgroup analysis of the SIRTAX trial. J Am Coll Cardiol. 2007;50(12):1123-31.

14. Hermiller JB, Fergus T, Pierson W, Su X, Sood P, Sudhir K, et al. Clinical and angiographic comparison of everolimus-eluting and paclitaxel-eluting stents in small coronary arteries: a post hoc analysis of the SPIRIT III randomized trial. Am Heart J. 2009;158(6):1005-10. 